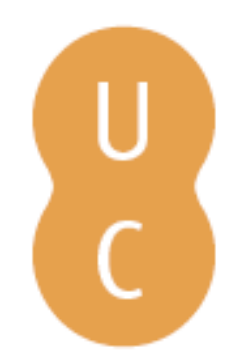

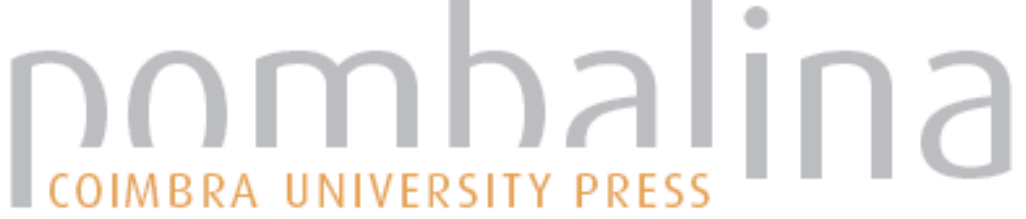

\section{Ideologia e retórica n'Os Lusíadas}

Autor(es): $\quad$ Silva, Luís de Oliveira

Publicado por: Imprensa da Universidade de Coimbra

URL

persistente: URI:http://hdl.handle.net/10316.2/30769

DOI: $\quad$ DOI:http://dx.doi.org/10.14195/978-989-26-0569-2_11

Accessed : $\quad$ 26-Apr-2023 12:46:52

A navegação consulta e descarregamento dos títulos inseridos nas Bibliotecas Digitais UC Digitalis, UC Pombalina e UC Impactum, pressupõem a aceitação plena e sem reservas dos Termos e Condições de Uso destas Bibliotecas Digitais, disponíveis em https://digitalis.uc.pt/pt-pt/termos.

Conforme exposto nos referidos Termos e Condições de Uso, o descarregamento de títulos de acesso restrito requer uma licença válida de autorização devendo o utilizador aceder ao(s) documento(s) a partir de um endereço de IP da instituição detentora da supramencionada licença.

Ao utilizador é apenas permitido o descarregamento para uso pessoal, pelo que o emprego do(s) título(s) descarregado(s) para outro fim, designadamente comercial, carece de autorização do respetivo autor ou editor da obra.

Na medida em que todas as obras da UC Digitalis se encontram protegidas pelo Código do Direito de Autor e Direitos Conexos e demais legislação aplicável, toda a cópia, parcial ou total, deste documento, nos casos em que é legalmente admitida, deverá conter ou fazer-se acompanhar por este aviso.

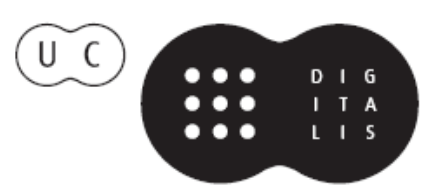




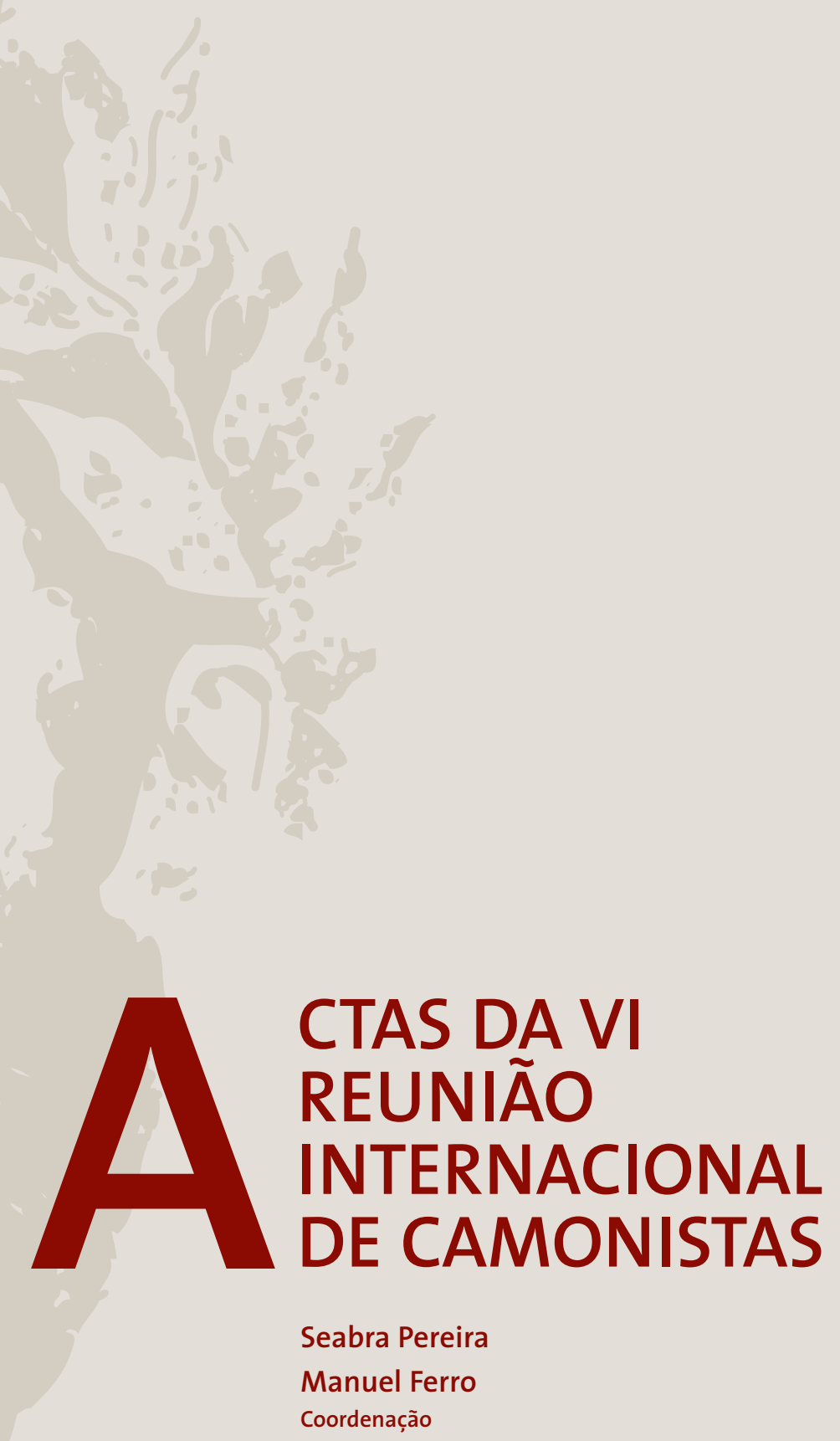


Luís de Oliveira e Silva

Universidade Nova de Lisboa

\section{IDEOLOGIA E RETÓRICA N'OS LUSÍADAS}

O poema epónimo de Virgílio está ligado a uma ocasiāo histórica proeminente, a vitória conseguida por Augusto frente a António e Cleópatra em Actium, no golfo de Ambrácia, a 2 de Setembro do ano 31 a.C. Dita vitória ocupa uma posiçáo central no escudo que Vulcano, a pedido de Vénus, forja para Eneias. A partir da Eneida, as obras ligadas hipertextualmente ao poema de Virgílio cobram uma feição abertamente política vinculada a uma concepção específica da História que incorpora a ideia de dominação ecuménica, a afirmação do sistema monárquico e a conseguinte apologia dinástica, anulando a temporalidade e atribuindo ao devir histórico uma densidade ontológica, ecfrástica, que acaba por constituir um inmobile continuum, no qual o passado se explica pela sua relação com o presente. Segundo afirma Julia Kristeva, a épica dá-nos a impressão de ser um discurso que modela o Espaço, mas que fica fora do Tempo. "A duração épica seria um instante em extensão, sem balanço e sem inversão, sem surpresa e sem expectativa, ACRÓNICA e AHISTÓRICA, portanto.» (Kristeva, 1984: p. 64). Como a batalha de Actium, a viagem de descobrimento do Gama representa uma viragem histórica que exige a estruturação de uma nova identidade nacional. $\mathrm{Na}$ peugada de Virgílio, numa época em que o processo de glorificação do Mantuano, empreendido durante a Idade Média e continuado por Vida, havia de atingir com Scalígero o grau de autêntica deificação literária (Spingarn, 1963: p. 9), Camóes pretende escrever um novo texto cultural capaz de revelar os valores de uma comunidade política cuja acção, que passa a desenvolver-se a escala universal, se vê submetida a um necessário redimensionamento. Nesta comunicação, deixando a um lado os indiscutíveis valores estéticos do poema, tratarei de evidenciar a função ideológica assumida pelo narrador de Os Lusíadas, potenciada mediante procedimentos retóricos, procurando enquadrar acçóes e personagens em parâmetros de ordem axiológica reveladores de atitudes morais e didácticas.

Num artigo publicado em 1936 (Matejca-Titunik, 1976: pp. 20-32), Petr Bogatyrev refere um tipo de texto literário cuja dominante não é, em modo algum, a função estética. Quando se escuta um hino nacional, por exemplo, a função estética é inevitavelmente relegada a um lugar subalterno. O respeito solene que o hino desperta no auditório é equivalente à veneração que o Estado lhe merece. Bogatyrev atribui o mesmo papel às "chansons de geste", às cançôes históricas russas - as bem conhecidas byliny que os camponeses chamavam stariny («coisas dos tempos antigos») - e às composições 
épicas jugoslavas. Este tipo de textos admite dois tipos de recepção. Uma, submetida a um processo empático de participação, que bem se poderia qualificar de mística, na qual a consciência do receptor se identifica completamente com o texto em imediata comunháo social. Outra, a recepção do leitor forâneo, que, ao não colaborar neste processo empático, poderá manter o distanciamento necessário para privilegiar a função estética do texto. Como Stanley Fish (1980: p. 15) deixou bem assente, a recepção de um texto por diferentes "interpretive communities» compromete a estabilidade da mensagem. É evidente que o herói sinedóquico de Os Lusíadas só poderá ser «o nosso Gama» (V.99) ou "o nosso Capitão esclarecido» (II.83) para um leitor português imerso no espírito da comunhão social. O poema camoniano, ao fim e ao cabo, reveste-se de um carácter autobiográfico peculiar, na medida em que a consciência individual se funde na consciência colectiva. Como diz Bakhtine, "se não me separo da vida cujo herói são os outros... eu próprio - o narrador dessa vida - pareço estar incorporado aos heróis dessa vida... e alcanço o estatuto de herói, anexando-me à minha narrativa; as formas pelas quais percebo os valores do outro se transferem para mim quando sou solidário com os outros. É assim que o narrador se torna herói» (1984: p. 168). Segundo ensina Perelman, recolhendo um topos da Retórica clássica, a interacção entre grupo e indivíduo baseia-se numa relação que admite plena convertibilidade. $\mathrm{O}$ valor de um acto desempenhado por um indivíduo traduz-se no prestígio do grupo e, por outro lado, o valor das façanhas protagonizadas pelo grupo acaba por reverter no prestígio do indivíduo. (Perelman, 1983: p. 434). Diferentemente de Virgílio, que por razóes óbvias não toma partido por nenhum dos actores do seu poema, a sensibilidade de Camóes, sem ter em conta que "elogio em boca própria é vitupério» (Figueiredo, 1987: p. 383), pende completamente para o lado dos Portugueses. Já Menelau, na Ilíada (XVII. 19), denunciara a impropriedade do louvor em boca própria. "Devemos considerar em presença de quem louvamos, porque, como Sócrates deixou dito não é difícil elogiar os Atenienses estando entre os Atenienses", escreveu Aristóteles (Retórica, 1367b), citando o Menexeno platónico. Segundo o mesmo Aristóteles, o louvor dos próprios feitos traduz descaro, impudência (anaiskhuntia) e é indício de adulação (kolakeia). (Retórica, 1383b). "Falar demoradamente sobre nós próprios... é sintoma de presunção» (alathoneia), escreve o Estagirita mais adiante. (Retórica, 1384a). "Omnis vitiosa iactatio est», escreveu Quintiliano. (XI.I.5) «Las propias alabanzas envilecen», confessava o Quixote a Don Diego de Miranda, o Cavaleiro do Verde Gabão (1984, II. XVI: p. 151). Pelo ânimo do Gama, ao encetar o seu discurso analéptico perante o Rei de Melinde, perpassa a suspeita de que as suas palavras poderão ser indecorosas:

"Que outrem possa louvar esforço alheio,

Cousa é que se costuma e se deseja;

Mas louvar os meus próprios arreceio

Que louvor tâo suspeito mal me esteja».

Camôes, no entanto, não pode conter o impulso epidíctico. "Quão doce é o louvor e a justa glória / Dos próprios feitos, quando são soados!', exclamará mais tarde (V.92), arrumando definitivamente a questão. 
É incontestável que o discurso demonstrativo de Camões tem uma base ideológica. António José Saraiva define Os Lusíadas como «o panegírico magnificente da nobreza nacional e a expressão fiel do ideal expansionista do Estado.» (1955, II: p. 150) e afirma que Camóes, no plano histórico do seu poema, «desenvolve uma ideologia feudal» (1955, II: pp. 683-684). Náo devemos, no entanto, proceder a uma paráfrase do conteúdo do poema para definir esta suposta ideologia, mas, depois de um exame aturado, tentar achá-la na complexidade textual que serve de veículo à sua semiotização. O poema de Camóes parece adaptar-se ao modelo de análise proveniente do estruturalismo genético de Lucien Goldman, segundo o qual um universo mais ou menos coerente, cujos fundamentos são elaborados de um modo aproximativo por um grupo social privilegiado, encontra a sua objectivação plena na obra de um autor eminente, cuja consciência acabará por revelar ao grupo as tendências de que este era portador, sem ter capacidade para as sistematizar, tendências que definiriam o seu pensamento, a sua afectividade e o seu comportamento. (Goldmann, 1979) Será preciso ter em conta, todavia, como sublinha Max Weber (1944, I: p. 9), que, detrás das afirmaçóes aparentemente positivas de qualquer autor, se podem esconder "motivos» pretextados e "repressóes», de modo que o testemunho subjectivo de Camóes, embora não tenhamos razóes suficientes para duvidar da sinceridade do poeta, só possui um valor relativo. Como revela Duchacek (1975: p. 227), num sistema político impregnado de ideologia, o credo vigente, promovido e propagado do berço ao túmulo, pode funcionar como um screen que só permite a passagem de um determinado tipo de informação selectiva, de modo a destacar a observação de determinados pormenores e a impedir a captação de outros. Hoje sabemos perfeitamente que as chamadas "culturas nacionais» são muito frequentemente uma projecção sobre o exterior de uma cultura dominante representativa de determinadas capas sociais mais do que do conjunto da população. (Preiswerk, 1975: p. 41) No mundo de Camóes, no qual o anonimato e a ignomínia se confundem, visto que no código épico o signo é análogo ao nome próprio, só os nobres são individualizados. Já Homero afirmava que os senhores são "melhores, mais valentes» (pherteroi) que "os homens do povo». Ao tratar daqueles que tombavam na batalha diz-nos Homero que náo poderá mencionar nem nomear a plethus, a plebe, a gente comum (Ilíada, II. p. 488). Camóes, fiel à diferenciação que Virgílio estabeleceu entre «bello clari» e "bello caduci», distingue os "Heróis esclarecidos» (IX.95), que se imortalizam ao tombar na guerra, cujos nomes são sempre mencionados, da massa anónima dos soldados e marinheiros desconhecidos, o «vulgo errante» (VII.85), o «vulgo vil sem nome» (IV.41).

Camóes vive dentro de um sistema dominado pelo que Krech (1948) chamou "uniformidade de informação». Neste sistema destaca, por um lado, a informação proveniente da Igreja, associação de dominação que aplica em seu proveito a coacção psíquica, ao conceder e recusar bens de salvação mediante o monopólio da «coacçáo hierocrática» (Weber, 1944, I: p. 54). Assim, n’Os Lusiadas, expansionismo territorial e expansão da Fé, a Fé e o Império que aparecem no poema unidos em série sindética bimembre, justificam-se reciprocamente. Estado e Igreja são complementares. O cristão, enquanto cidadão dos dois mundos, está organicamente afiliado a uma só organização social. Podem-se distinguir nesta organização dois elementos constitutivos, a Igreja e o Estado, que no fundo estáo coadunados numa unidade indissolúvel pelo fim último de todos os actos terrenos: a união com Deus na "visão beatífica" a que 
está destinado o homem. Camóes, aderindo à doutrina de Santo Tomás e às ideias de Egídio Romano («nulla temporalia sunt sub Cesare que non sint sub ecclesia»), e opondose à tradição de Guilherme de Occam e Marsílio de Pádua, que negava as aspiraçóes teocráticas do Papado, defende a unidade eclesiástica da civilização, sob o Império de Roma, considerando o Sumo Pontífice como o elo superior da cadeia que eleva o homem até Deus. Por outro lado, defende o poder político centralizado, arrogado em representante único e necessário da Nação, poder que, num grupo humano unido por uma comunidade de língua, de religião, de costumes e de "destino», permite a criação de um tipo especial de pathos no qual a consciência individual acaba por fundir-se na mentalidade colectiva. Segundo Weber, este tipo de orgulho patético costuma estar mais estendido numa comunidade de dimensôes pequenas do que noutra de uma dimensão muito maior. O poema camoniano trata de legitimar unilateralmente um tipo de dominação simultaneamente tradicional e carismática para o qual Camóes, nas suas intrusôes metaliterárias, embora trate por vezes de corrigir os seus excessos e dislates, não pode encontrar alternativa válida. Assim, a História de Portugal relatada longamente por Vasco da Gama ao Rei de Melinde, que o escuta com uma paciência digna de Job, não é outra coisa que a história da Monarquia Portuguesa, sendo a monarquia a única modalidade política que Camóes é capaz de conceber. E sempre de direito divino, modalidade de legitimação à qual nem sequer escapa o ínfido Rei de Melinde (II.79).

Os valores senhoriais, que impregnam todo o poema, apelam à "honra» e à «fidelidade» pessoal como motivos constitutivos da acção. O sentimento cavalheiresco da dignidade, segundo ensina Weber (1944, IV. p. 246), medra dentro do culto pessoal e representa, portanto, o pólo contrário de todo o tipo de relaçóes objectivas, de relaçôes de "negócio», vínculos que na ética feudal foram sempre considerados como algo especificamente indigno e ruim. O feudalismo menospreza a objectividade burguesa e o seu "modus vivendi» é totalmente alheio ao espírito económico racional. $\mathrm{Na}$ estruturação feudal de dominação tradicional, o soberano não é somente um superior hierárquico, mas um senhor pessoal. O seu quadro administrativo não é constituído por funcionários, mas por criados. As relaçóes do quadro administrativo com o soberano não são determinadas pelas obrigaçôes objectivas do cargo, mas sim pela fidelidade - a "grão fidelidade Portuguesa» (III.41) realizada paradigmaticamente por Egas Moniz -, que é um vínculo pessoal que une o servidor ao seu senhor. Fidelidade que se traduz na sua realização prática: a obediência. $\mathrm{O}$ vassalo, termo que aparece nove vezes n'Os Lusiadas (II.84; III.36; III.41; IV.19; VI.30; VIII.12; VII.13; X.25; X.146), está unido ao Senhor por laços de amor, fidelidade, lealdade e obediência. "Fidelidade, lealdade" e "amor" contrapóem-se a "traição, aleive" e "inimizade", termos que definem a quebra do compromisso vassálico. (Mattoso, 1989: p. 304) O engano e a injustiça são inconsistentes com o amor. "Jo ne vous aim nëent», dizia o traidor Ganelon a Roland. Camóes não duvida em retirar ao valente Fernão de Magalhães, que se pôs ao serviço do Rei de Castela, quebrando o compromisso vassálico, metade da sua nacionalidade: "O Magalhães, no feito, com verdade, / Português, porém não na lealdade» (X.140).

Do amor que une os heróis de Os Lusiadas à Pátria e ao Rei participa também o narrador do poema. "Vereis amor da pátria, não movido / De prémio vil, mas alto e quase eterno", afirma ele na dedicatória a D. Sebastião. (I.10) No entanto, mais tarde, traídas 
as suas expectativas, dá a entender que esse amor não será tão altruísta como isso ao dizer: "A troco dos descansos que esperava, I Das capelas de louro que me honrassem, I Trabalhos nunca usados me inventaram, / Com que em tão duro estado me deitaram!» (VII.81) Os poetas, em Portugal, estão longe de conseguir "Honra, prémio, favor que as artes criam» (VIII.39), já que a Pátria lhes nega "O favor com que mais se acende 0 engenho» (X.145). Só na Ilha dos Amores, e portanto a um nível utópico-transcendental, hão-de conseguir a merecida compensação, a glória e a riqueza que a realidade lhes nega, quando as Ninfas solidárias "Os ornam de capelas deleitosas / De louro e de ouro e flores abundantes». (IX.84) Os chefes da expedição chefiada pelo Gama, apesar do amor desinteressado que reclamam para si, "Foram de Emanuel remunerados / Por que com mais amor se apercebessem». (IV.83) Camóes acaba por trair a magnanimidade excessiva dos Portugueses ao revelar, inadvertidamente, a sua base material. Benefícios e prebendas acrescentam o amor que os Portugueses nutrem pelo seu Rei.

A ideologia é o lugar simbólico onde o poder é incessantemente legitimado ou contestado, reforçado ou enfraquecido (Ansart, 1977, p. 11). A ideologia política, em particular, permite a constituição e renovação de um imaginário colectivo mediante o qual a comunidade define a sua identidade, as suas aspiraçôes e as grandes linhas da sua organização. É bem conhecida a doutrina de Althusser, segundo a qual toda ideologia representa uma relação imaginária dos indivíduos com as suas condiçốes reais de existência. Toda ideologia contém, na sua deformação necessariamente fantástica, não as relaçôes de produção objectivamente existentes, mas a relação imaginária dos indivíduos com as relaçóes reais em que vivem. (Althusser, 1974, p. 71) Não quer isto dizer que toda ideologia seja falsa. Quer dizer, isso sim, que qualquer alusão ideológica à realidade objectiva se transforma, em certa medida, em ilusão. Ferruccio Rossi-Landi equipara ideologia a "falsa consciência». (1980: p. 144) Ou melhor, teremos "falsa consciência» a um baixo nível de elaboração conceptual e ideologia a um nível de conceptualização mais elevado. A ideologia será, pois, falsa consciência convertida em falso pensamento através da elaboração linguística, falsa consciência na qual a programação atingiu o nível linguístico. (Rossi-Landi, 1980: p. 146) Uma ideologia conservadora, como é a que informa o poema camoniano, não pretenderá mais que programar a prática social de acordo com um modelo de reprodução cuja definição parte de uma estrutura hierárquica centralizada. A ordem cantada por Camóes, que implica a defesa e a justificação do imperialismo, numa sociedade regida pelo direito divino e pelo absolutismo monárquico, é um imenso artefacto que, segundo palavras que Octavio Paz (1993. p. 251) aplica à estrutura colonial espanhola, estava "destinado a durar pero no a transformarse». Esta construçáo ecfrástica da História precisava, pois, de apresentar o seu próprio discurso como náo-ideológico, como extra-histórico, atribuindo-lhe eficácia ontológica ao neutralizar a necessária evolução diacrónica, fundindo o presente no passado, assimilando o passado ao presente. Daí a recursividade isotópica, sobretudo a nível axiológico, da História de Portugal que Camôes nos relata, numa sincronização absoluta de valores dominada pela axiologia quinhentista. Os valores do passado são assimilados aos valores do presente, facto que implica uma completa neutralização da diacronia e que acaba por desembocar numa sincronização paradoxal do devir histórico. Através da fixação linguística, Camóes procede a um congelamento de representaçôes conceptuais. No entanto, o código axiológico do Renascimento, na sua enorme distensão polissémica, é complexo 
e contraditório e nem sempre se presta a sistematizações unívocas. Agnes Heller (1982, p. 23) expóe algumas destas contradiçôes. Para Castiglione ou Maquiavel, a «sede de glória» é virtude destacada. Cardano, pelo contrário, rejeita-a. Para Vassari, a «altivez» deve ser objecto de respeito; para Thomas More é fonte dos maiores pecados. Petrarca e Shakespeare consideram a paixão pela vingança perversa e desprovida de sentido; Bacon coloca-a entre os valores positivos. O valor da moderação tem uma importância central para Pico de la Mirandola, mas Giordano Bruno defende a imoderação das paixóes.

O código axiológico de Camóes assenta num espaço no qual confluem valores medievais e valores renascentistas. Terá que conciliar, em primeiro lugar, as virtudes cardiais, de estirpe aristotélica, que dominam a tradição épica, com as virtudes teologais emanadas do Cristianismo. Se, como escreve Jaime Cortesão (1960, p. 106), "não oferece hoje contestação possivel que o objectivo supremo do descobrimento marítimo para a Índia foi o tráfico rico do Oriente», Camóes, na peugada dos cronistas do seu tempo, tratará de ocultar esta motivação positiva e laica. Quando os navegantes divisam finalmente terra de Calecut, Camôes interrompe a narração para se espraiar, ao longo de cinco estâncias, numa meditação sobre a glória e a virtude. (VI.95-99) Se, pouco depois, perante a visão imediata do proveito económico, Camóes grita com mal contido alvoroço:

"Já sois chegados, já tendes diante

A terra de riquezas abundante!»

(VII.1)

não o faz sem ter antes afirmado que o prémio dos trabalhos e temores despendidos se cifra no acréscimo da kalokagathia dos Portugueses.

A determinação de nobilitar um empreendimento comercial leva Camões a atribuirlhe dignidade épica, o que o obriga a suprimir o interesse económico como móbil da acção. Ao propor ao Samorim a aliança comercial que D. Manuel lhe tinha encomendado negociar, o Gama afirma que o êxito do contrato redundará em "proveito» do rei gentil e em "glória ingente» do monarca português. Vale a pena transcrever integralmente a estância em questão, que, a nosso ver, contém marcas evidentes de ironia:

«E, se queres, com pactos e lianças

De paz e de amizade, sacra e nua,

Comércio consentir das abundanças

Das fazendas da terra sua e tua,

Por que creçam as rendas e abastanças

(Por quem a gente mais trabalha e sua)

De vossos Reinos, será certamente

De ti proveito, e dele glória ingente»

(VII.62)

Alonso de Ercilla, o poeta de La Araucana (1569-1590), que descreve a conquista do Chile pelos Espanhóis partindo frequentemente da perspectiva dos vencidos, deconstrói, através do discurso do bárbaro Galbarino, o álibi religioso da evangelização. 
Vale a pena transcrever parte desse discurso, já que ele vem complementar e acentuar a conhecida contra-argumentaçáo do Velho do Restelo:

"Y es un color, es aparencia vana

querer mostrar que el principal intento

fue el extender la religión cristiana

siendo el puro interés su fundamento;

su pretensión de la codicia mana,

que todo lo demás es fingimiento

pues los vemos que son más que otras gentes

adúlteros, ladrones, insolentes»

(1979, II, XXIII. p. 13)

Se, a nível interno, as relaçóes de poder são definidas por um grupo primário, por uma clique cujos componentes se caracterizam pela tendência a fundirem-se num todo comum no qual se diluem os interesses individuais, ao nível das relaçôes externas este grupo adopta um modo diferente de afirmação. Os valores da Comunidade Lusíada estáo esteados numa visão etnocêntrica exclusivista. O etnocentrismo, como ensina Preiswerk (1975, p. 49), conduz a um comportamento projectivo estritamente monológico que interpreta o "out-group» de acordo com o modo de pensamento do «in-group», impedindo qualquer tipo de diálogo cultural. Como afirma Lotman (1992, p. 63), este tipo de cultura etnocêntrica, ao criar a sua organização interna, cria simultaneamente a desorganização externa. Assim, as estruturas situadas além dos confins semióticos adoptados são declaradas não-estruturas. O Português, cristão e civilizado, depositário de uma ordem (kosmos), opóe-se aos «cafres selvagens» (X.38), à «selvática gente, negra e nua» (X.93) que habita "as terras viciosas / de Africa e de Asia» (I.2), gentes que, segundo Camóes, vivem afundadas na desordem, no caos. Por outro lado, o Português opóe-se ao Mouro, a quem náo pode negar entidade cultural, na medida em que a cultura se opóe à anticultura, ou seja, na medida em que a verdade se contrapóe à falsidade. Os representantes do Islão, da "errada Seita», sequazes do "Profeta falso e noto» (VIII.47), do "falso Mahamede» (II.50), que se opóe ao "Cristo verdadeiro» (X.111), são submetidos sistematicamente a uma adjectivação degradante. São "bruta gente» (I.92), «malina gente» (I.99), «infiel e falsa gente» (II.6), «Pérfida, inimiga e falsa gente» (II.8), "os Perros» (III.48), "o povo imundo» (VII.2), e assim por diante. Este tipo de Retórica, na qual a afirmaçáo da identidade do grupo passa pela negação e aviltamento da identidade alheia, renuncia a qualquer tipo de argumentação dialéctica, impedindo a visão da diversidade cultural como complexo de contrastes.

Tanto os Portugueses como os seus adversários são definidos no poema mediante procedimentos de estereotipização. Como ensina Preiswerk (1975, p. 238), o estereótipo é um tipo de representação que aplica automaticamente um mesmo modelo rígido a cada um dos membros de um grupo determinado. A visão estereotípica impede a captação da individualidade, ao dilui-la nas características globais do grupo, e acaba por constituir uma redução brutal da complexidade inerente à realidade. Camóes, preocupado sobretudo por uma legitimação unilateral da história, utiliza uma terminologia hiperbolicamente positiva com relação ao "in-group» que tem como 
pólo contrário uma terminologia negativa estereotipizada sempre que se refere ao "out-group».

A Retórica, antes que a Idade Moderna restringisse o seu âmbito, transformando-a num simples armazém de tropos, estava intimamente unida à dialéctica. E a dialéctica, como afirma Paolo Valesio (1986, p. 114), é a arma mais potente que pode ser utilizada contra os assaltos, subtis e contínuos, da Ideologia. Com a Retórica restrita, com a Retórica divorciada da dialéctica, a Retórica acaba por transformar-se em Ideologia. Em ideologia rígida, petrificada, que não é outra coisa que Retórica degradada. Claude-Gilbert Dubois (1979: p. 222), ao delimitar o Maneirismo, encontra marcas de paranóia nos sistemas absolutistas e totalitários, resultado de um delírio egocêntrico e megalómano que pôe em cena uma representação unívoca e hiperbólica do sujeito, que muitas vezes não passa de ser uma reacção defensiva a um sentimento de angústia e frustração. É este delírio megalomaníaco o que o Velho do Restelo, na sua intervenção dialógica, trata de desmantelar, opondo à ideologia oficial marcas de uma ideologia periférica alternativa, e conferindo ao poema, por vez primeira, uma inesperada tensão dialéctica. Como escreve John Frow (1988: p. 63), se a função do investimento ideológico (no sentido freudiano de Besetzung) se traduz na aceitação ou tolerância da posição hegemónica da classe dominante, a resistência a essa aceitação acaba por inscrever-se, inevitavelmente, na estrutura do próprio discurso que se empenha em afirmá-la. Segundo Jacques Lacan (1966: p. 813; Bellamy: 1992, p. 10), qualquer declaraçáo de autoridade náo conta com outra garantia que náo seja a sua própria enunciação, e de nada servirá procurá-la noutro significante. O Velho do Restelo, partindo de repressóes inconscientes ou de ocultaçôes deliberadas ínsitas no poema, faz uma leitura antitética do código épico, transformando os conceitos-chave da epopeia em noçôes divergentes e assintéticas. Assim, a glória de mandar é vã cobiça e esforço e valentia passam a ser crueza e feridade. Do mesmo modo, a sede de fama não é mais que vaidade mesquinha. Camóes, ao longo do seu discurso, procura ineficazmente sintetizar tese e antítese. Maquiavel (1983: pp. 251-252), antecipando-se a Nietzsche, expôe perfeitamente uma das contradiçóes que Camóes se vê obrigado a encarar: "La nostra religione ha glorificato piu gli uomini umili e contemplativi che gli attivi. Ha dipoi posto il sommo bene nella umiltà, abiezione, e nel despregio delle cose umana: quell'altra lo poneva nella grandezza dello animo, nella fortezza del corpo ed in tutti le altre cose atte a fare gli uomini fortissimi». (Maquiavel, 1983, p. 251-52) É preciso ter em conta que Camóes se inscreve numa tradição que acreditava nas qualidades detergentes do sangue islâmico. Os Infantes, aquando da conquista de Ceuta, segundo conta Zurara, gozavam sobremaneira «lavando suas mãos no sangue dos infiéis». (1992, p. 41) Diz o cronista mais adiante: "E viam-se (os Infantes) no meio daquela cidade envoltos entre os mouros, alegrando-se com o espalhamento do seu sangue. E tanta doçura sentiam em tais imaginaçôes, que lhes pesava, quando se the oferecia cousa por que se tiravam delas». (1992, p. 64) Caridade cristã e violência expansionista, que como o vinho e o azeite não se misturam, aspiram a ser sintetizadas no "Pois só por teu serviço navegamos" de Camóes (II.32) que procura diluir o pragma da violência no caldo espiritual da expansão evangélica, síntese desautorizada, sem ir mais longe, pelo irenismo erasmista do Quinhentos. Veja-se, a título de exemplo, as palavras que o sábio de Roterdão endereçava a Paul Voltz, em 1518: "Et de vrai, le moyen le plus convenable por nous de prouver que nous sommes fortement chrètiens, ce n'est pas d'avoir tué le plus grand nombre 
de Turcs, mais d'en avoir sauvé le plus grand nombre possible... Et à supposer que tombent hereusement les dés de la guerre qui est toujours chanceuse, il arrivera que le pontife et ses cardinaux étendent peut-être leur empire, mais non pas que le Christ étende le sien, car son règne n'est florissant que si prospèrent la piété, la charité, la paix, la chasteté..." (1971: p. 73) Náo de outra maneira agia o governo dos Estados Unidos da América, durante a Guerra Fria, ao justificar as suas contínuas agressóes com o argumento da cruzada em defesa da Liberdade, quando o que realmente estava em jogo eram os interesses da General Motors, da Standard Oil, da General Electric ou da Coca-Cola, receosas de que o comunismo lhes fechasse o acesso a determinados mercados. A visão antitética do Velho do Restelo tem uma grande importância no texto camoniano devido à sua estrutura adialéctica, na qual tese e antítese permanecem insolidárias, desobedientes a qualquer tentativa de unificação e superação sintética. Ao fim e ao cabo, e o Velho do Restelo sabe-o bem, da hiperbolização patética ao esvaziamento batético só há um passo. "Misera sorte! Estranha condição!» (IV.104)

\section{Bibliografia}

ALTHUSSER, Louis (1974), Ideologia e Aparelhos Ideológicos do Estado, Lisboa, Presença-Martins Fontes ANSART, Pierre (1977), Idéologies, Conflits et Pouvoir, Paris, Presses Universitaires de France

ARISTÓTELES (1975), The “Art” of Rhetoric, tr. John Henry Freese, Cambridge. Mass.- London, Harvard University Press-William Heinemann

BAKHTIN, Mikhaïl (1992), Estética da Criação Verbal, São Paulo, Martins Fontes

BELLAMY, Elizabeth J. (1992), Translations of Power. Narcissism and the Unconscious in Epic History, Ithaca and London, Cornell University Press

BOGATYREV, Petr (1976), Folk Song from a Functional Point of View, em Matejka-Titunik (1976), pp. $20-32$

CAMÓES, Luís de (1987), Os Lusiadas, ed. Emanuel Paulo Ramos, Porto, Porto Editora

CERVANTES, Miguel (1989), El Ingenioso Hidalgo Don Quijote de la Mancha, ed. Luis Andrés Murillo, Madrid, Castalia

CORTESÃO, Jaime (1960), A Política de Sigilo nos Descobrimentos, Lisboa, Comissão Executiva das Comemorações do Quinto Centenário da Morte do Infante D. Henrique

DUBOIS, Claude-Gilbert (1979), Le maniérisme, Paris, Presses Universitaires de France

DUCHACEK, Ivo D. (1975), Nations and Men: an Introduction to International Politics, Hinsdale, Illinois, The Dryden Press

ERCILLA, Alonso de (1979), La Araucana, ed. Marcos Morínigo e Isaias Lerner, Madrid, Castalia

ERASMO (1971), Enchiridion Militis Christiani, tr. A.J.Festugière, Paris, Vrin

FIGUEIREDO, Fidelino de (1987), A Épica Portuguesa no Século XVI, Lisboa, Imprensa Nacional-Casa da Moeda

FISH, Stanley (1980), Is There a Text in This Class?, Cambridge, Mass.- London, Harvard University Press

FROW, John (1988), Marxism and Literary History, Oxford, Blackwell

GOLDMANN, Lucien (1979), Pour une sociologie du roman, Paris, Gallimard

HELLER, Agnes (1982), O Homem do Renascimento, Lisboa, Presença

HOMERO (1988), The Iliad, tr. A. T. Murray, Cambridge, Mass-London, Harvard University PressWilliam Heinemann

KRECH J., CRUTCHFIELD, W. (1948), Theory and Problems of Social Psychology, New York, MacGrawHill

KRISTEVA, Julia (1984), O Texto do Romance, Lisboa, Horizonte

LACAN, Jacques (1966), Subversion du sujet et dialectique du désir dans l'inconscient freudien, in Écrits, pp.793-827, Paris, Seuil

LOTMAN, Jurij M. (1992), La Semioesfera, Venezia, Marsilio 
MACHIAVELLI, Niccolò (1983), Discorsi sopra la Prima Deca di Tito Livio, in Il Principe e altre opere politiche, Milano, Garzanti

MATEJCA, Ladislav, TITUNIK, Irwin P. Ed., (1976) Semiotics of Art: Prague School Contributions, Cambridge, Mass.-London, MIT

MATTOSO, José (1989), O Léxico Feudal, in En torno al Feudalismo Hispânico. I Congreso de Estudios Medievales, Ávila, Fundación Sánchez Albornoz

PAZ, Octavio (1993), El laberinto de la soledad, Madrid, Cátedra

PERELMAN, Chaïm, OLBRECHTS-TYTECA, Lucie (1983), Traité de l'argumentation: la nouvelle rhétorique, Bruxelles, Éditions de l’Université de Bruxelles

PREISWERK, Roy, PERROT, Dominique (1975), Ethnocentrisme et Histoire, Paris, Anthropos

QUINTILIANO, Marcus Fabius (1980), Institutio Oratoria, Cambridge, Mass.-London, Harvard University Press-William Heinemann

ROSSI-LANDI, Ferruccio (1980), Ideología, Barcelona, Labor

SARAIVA, António José (1955), História da Cultura em Portugal, Lisboa, Jornal do Foro

SPINGARN, J.E. (1963), A History of Literary Criticism in the Renaissance, New York, Harcourt, Brace \& World

VALESIO, Paolo (1986), Ascoltare il silenzio: la retorica come teoria, Bologna, Il Mulino

VIRGílIO (1953), The Aeneid, tr. H. Rushton Fairclough, Cambridge, Mass.-London, Harvard University Press-William Heinemann,

WEBER, Max (1944), Economía y Sociedad, México, Fondo de Cultura Económica

ZURARA, Gomes Eanes de (1992), Crónica da Tomada de Ceuta, ed. Reis Brasil, Lisboa, EuropaAmérica 